\title{
Cretobrachygluta gen. nov., the first and oldest Brachyglutini in mid-Cretaceous amber from Myanmar (Coleoptera: Staphylinidae: Pselaphinae)
}

\author{
Zi-Wei YIN ${ }^{1, *)}$, Sergey A. KURBATOV²), Giulio CUCCODORO ${ }^{3)} \&$ Chen-Yang CAI $^{4,5, *)}$ \\ ${ }^{1)}$ Laboratory of Environmental Entomology, College of Life Sciences, Shanghai Normal University, Shanghai, 200234, P. R. China \\ 2) Museum of Entomology, All-Russian Plant Quarantine Center, Pogranichnaya 32, Bykovo 140150, Russia \\ ${ }^{3)}$ Muséum d'histoire naturelle, Case postale 6434, CH-1211 Genève 6, Switzerland \\ ${ }^{4}$ CAS Key Laboratory of Economic Stratigraphy and Palaeogeography, Center for Excellence in Life and Paleoenvironment, Nanjing Institute of \\ Geology and Palaeontology, Chinese Academy of Sciences, Nanjing 210008, P. R. China \\ ${ }^{5)}$ School of Earth Sciences, University of Bristol, Life Sciences Building, Tyndall Avenue, Bristol BS8 1TQ, United Kingdom \\ *) Corresponding authors, e-mails: pselaphinae@gmail.com; cycai@nigpas.ac.cn
}

\author{
Accepted: \\ $1^{\text {st }}$ March 2019 \\ Published online: \\ $4^{\text {th }}$ March 2019
}

\begin{abstract}
A new fossil genus and species of the subfamily Pselaphinae (Coleoptera: Staphylinidae), $\uparrow$ Cretobrachygluta laurasiensis gen. et sp. nov., is described based on an exquisitely preserved specimen in mid-Cretaceous amber from northern Myanmar. The new genus possesses a series of characters diagnostic of the extant Brachyglutini: Brachyglutina (supertribe Goniaceritae), but it also exhibits several plesiomorphic traits that suggest a basal position within the tribe. The discovery of the first and oldest brachyglutine beetle in Burmese amber considerably improves our understanding of the early morphological evolution of Pselaphinae during the Mesozoic Era.
\end{abstract}

Key words. Coleoptera, Staphylinidae, Pselaphinae, fossil, Burmese amber, taxonomy, character evolution

Zoobank: http://zoobank.org/urn:1sid:zoobank.org:pub:92E283C0-30BB-4610-8D48-12B40CF9B425

(C) 2019 The Authors. This work is licensed under the Creative Commons Attribution-NonCommercial-NoDerivs 3.0 Licence.

\section{Introduction}

With 10,120 extant species classified in 40 tribes and 1259 genera (A. F. Newton, pers. comm., data provided on $27^{\text {th }}$ February 2019), the ant-loving beetle subfamily Pselaphinae represents a major clade of terrestrial arthropods. Six supertribes, viz., Faronitae, Euplectitae, Goniaceritae, Batrisitae, Pselaphitae, and Clavigeritae, are currently recognized within Pselaphinae, but except for a sister group relationship between Faronitae and the other supertribes, the internal phylogeny and monophyly of the remaining supertribes (or even many tribes!) are left largely unresolved (Newton \& Thayer 1995, ChandLER 2001, PARKER 2016). This is probably due to the lack of a comprehensive phylogeny covering all pselaphine tribes, either morphologically or molecularly, as well as a scarcity of published fossil records that may be key to understanding the historical biogeography and character evolution of the group as a whole. A detailed introduction of the fossil history of Pselaphinae was provided by PARKER (2016) and Yin et al. (2017).

The extant tribe Brachyglutini is a diverse group represented by 117 genera, with a majority of them occurring on landmasses of a Gondwanan origin (NEWTON \& CHANDLER 1989, PARKER 2016). In contrast to this astonishing modern diversity, their fossil records are limited to the few insufficient records from Eocene Baltic amber (e.g., SchAufuss 1890) and Cenozoic Australian amber (e.g., OKE 1957), and are completely lacking from Mesozoic deposits. Here we report the discovery of the first and oldest Brachyglutini based on a well-preserved specimen in mid-Cretaceous amber from northern Myanmar (ca. $99 \mathrm{Ma}$ ), and discuss its placement base on morphological features. The new find considerably improves our understanding of the early morphological evolution of the pselaphines currently grouped in Goniaceritae. 


\section{Material and methods}

The holotype is deposited in the Insect Collection of Shanghai Normal University, Shanghai, P. R. China (SNUC). The fossil specimen described here was collected from an amber deposit in the Hukawng Valley of Kachin, northern Myanmar (26²1'33.41"N, 9643'11.88"E; Cruickshank \& Ko 2003, Grimaldi \& Ross 2017). Maps showing the amber-yielding locality and the amber forest some 99 million years ago were provided in KANIA et al. (2015) and YIN et al. (2018). The age of Burmese amber, once regarded as Eocene age (CHHIBBER 1934), has been recently established as the earliest Cenomanian (98.79 \pm $0.62 \mathrm{Ma}$ ) based on U-Pb dating of zircons (SHI et al. 2012), which agrees with a general age suggested by GRIMALDI et al. (2002) based on key bioinclusions. However, different workers have suggested slightly older ages, either within the late Albian (Cruickshank \& Ko 2003, Ross et al. 2010), or near the Albian-Cenomanian boundary (RASNitsYn et al. 2016, MaO et al. 2018). In this paper, the age of Burmese amber is referred to as upper Albian to lower Cenomanian.

The amber was cut using a handheld engraving tool and polished using sandpapers of different grits and rare earth polishing powder. Habitus pictures of the fossil were made using a Canon EOS 5D Mark III digital camera, equipped with a Canon MP-E 65mm f/2.8 1-5× macro photo lens, and a Canon MT-24EX Macro Twin Lite flash as light source; figure $2 \mathrm{~A}$ was produced using a Zeiss Axio Imager 2 light microscope with an attached digital camera under fluorescent lighting. Montage photos were produced in Zerene Stacker ver. 1.04; and all images were optimized and grouped in Adobe Photoshop CS5 Extended.

The terminology applied in this paper follows that of Chandler (2001), except we use 'ventrite' instead of 'sternite' (LAWRENCE et al. 2010) when discussing meso- and metathoracic structures.

\section{Taxonomy}

Family Staphylinidae Latreille, 1802

Subfamily Pselaphinae Latreille, 1802

Supertribe Goniaceritae Reitter, 1882

Tribe Brachyglutini Raffray, 1904

\section{$\uparrow$ Cretobrachygluta gen. nov.} (Figs 1-2)

Type species. $†$ Cretobrachygluta laurasiensis sp. nov., here designated.

Diagnosis. Head with small, nude vertexal foveae, lacking sulcus connecting foveae; antennae with club formed by apical three antennomeres; gular region with broad median ridge. Pronotum with small, nude median and lateral antebasal foveae. Each elytron with four basal foveae; subhumeral foveae and marginal striae present; discal striae absent. Metacoxae contiguous, moderately projecting posteriorly; tarsomere 2 distinctly shorter than tarsomere 3; tarsi each with single pretarsal claw. Abdomen with tergite 1 (IV) much longer than 2 (V); tergites 1-4 (IV-VII) with broad paratergites; tergite 1 (IV) with two basolateral foveae, lacking mediobasal fovea; sternite 1 (III) as long as 2 (IV) along midline.

Description. Body length slightly over $1.8 \mathrm{~mm}$; habitus (Fig. 1) strongly convex dorso-ventrally, in dorsal view strongly broadened posterior to pronotum.

Head (Fig. 2B) roundly quadrate, slightly wider than pronotum; vertex raised, with pair of small and nude vertexal foveae (Fig. 2A; vf); frons shallowly and broadly impressed, impression flanked laterally by widely separated antennal tubercles, and demarcated anteriorly by broad frontal-clypeal ridge; ocular-mandibular carinae (Fig. 2D; omc) distinct; gular region broadly impressed at middle, two close but clearly separated foveae (Fig. $2 \mathrm{C}$; $g f$ ) in impression; broad, longitudinally oval median gular ridge present anterior to foveae and extending to mouthparts, demarcated laterally by sulci. Antennae (Fig. 2A) eleven-segmented; club well-developed, formed by apical three antennomeres, with sub-oval and basally truncate antennomeres 11 (Fig. 2A; a11) much wider than preceding antennomeres. Maxillary palpi four-segmented; palpomere 1 minute, elongate, palpomere 2 pedunculate in basal half, strongly broadening toward apex, palpomere 3 subtriangular, approximately as wide and half as long as palpomere 4, palpomere 4 (Fig. 2B; mp 4) largest, sub-oval, with elongate apical palpal cone.

Pronotum (Fig. 2B) slightly elongate, widest at apical third; lateral margins rounded, sides convergent toward apex at apical two-fifths and narrowing toward base at basal third; disc with nude median (Fig. 2B; maf) and lateral antebasal (Fig. 2B; laf) foveae subequal in size, lacking additional carinae, sulci or tubercles; paranotal carinae either short, or lacking; lateral procoxal foveae present, moderately separated.

Elytra (Fig. 2B) slightly wider than long, widest point posterior to middle; each elytron with four small but distinct basal foveae (Fig. 2B; bef); sutural striae (Fig. 2B; ss) complete; discal striae absent; subhumeral foveae (Figs 2B, 2D; shef) present; short marginal striae (Figs 2B, 2D; $m s$ ) extending from subhumeral foveae to basal third of elytral length; posterolateral clefts (Fig. 2B; plc) broad and shallow. Hind wings fully developed.

Thorax with narrowly separated median mesoventral foveae (Fig. 2C; mmsf); lateral mesoventral foveae (Fig. 2D; lmsf) simple; lateral mesocoxal foveae (Fig. 2C; lmcf) and lateral metaventral foveae (Fig. $2 \mathrm{C}$; lmtf) present; lateral sutures separating meso- and metaventrite well-marked, fully developed; posterior margin of metaventrite with narrow split at middle.

Abdomen (Figs 2A-C) dorsoventrally flattened, with generally rounded lateral margins; segments telescoping. Five tergites (IV-VIII) (Figs 2A, 2B; tIV-VIII) visible, with broad paratergites on segments $1-4$ (IV-VII); tergite 1 (IV) much longer than tergite $2(\mathrm{~V})$, sides narrowing toward base, lacking mediobasal foveae, with pair of basolateral foveae (Fig. 2B; blf), short triangular discal carinae (Fig. $2 \mathrm{~B}$; dc), and broad, shallow transverse impression at base. Six sternites (III-VIII) (Fig. 2C; sIII-VIII) visible; sternites 1 (III) and 2 (IV) subequal in length along midline; sternite 

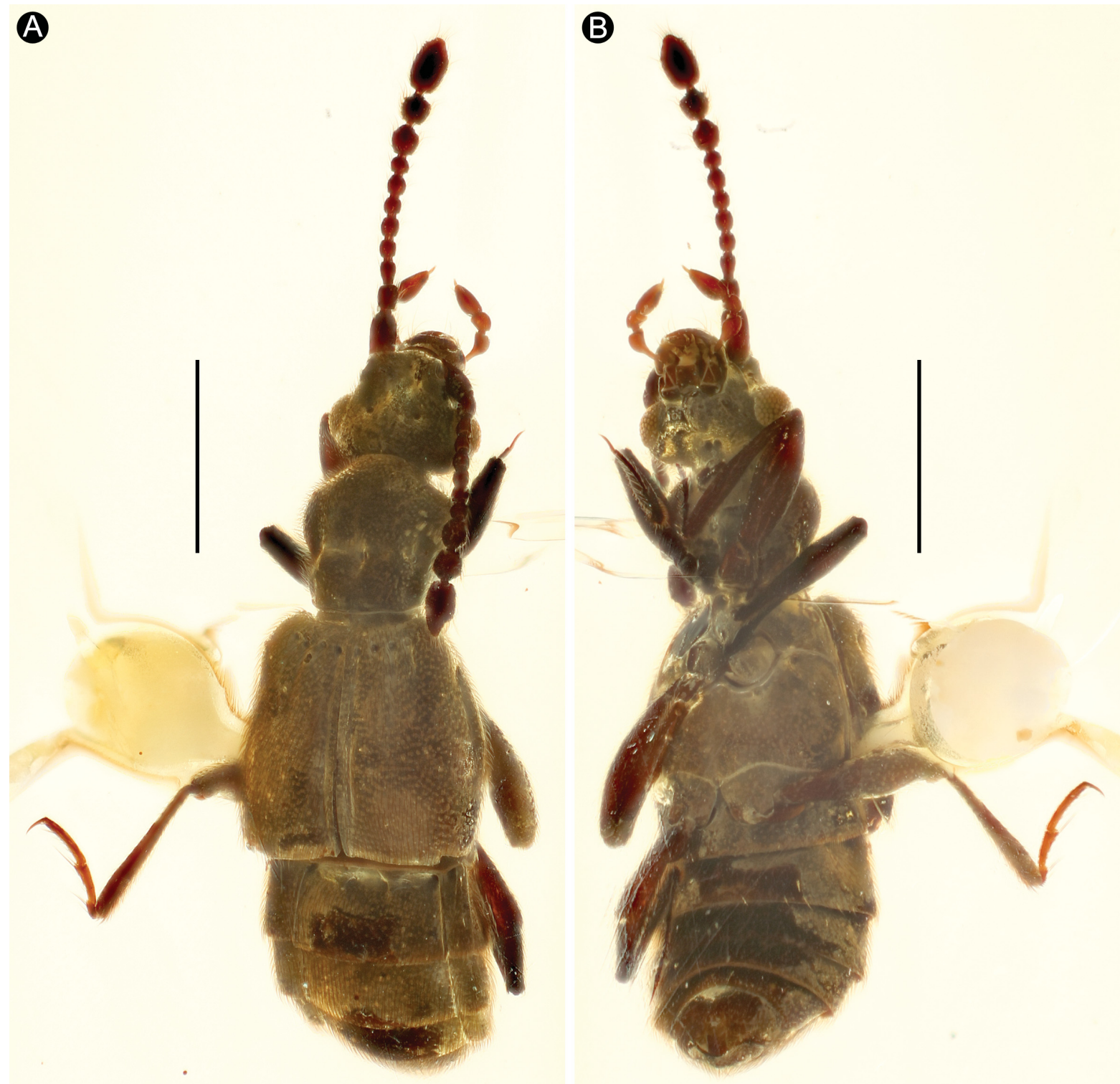

Fig. 1. Habitus of $\uparrow$ Cretobrachygluta laurasiensis gen. et sp. nov. A - dorsal view; B - ventral view. Scale bar: 0.5 mm.

2 (IV) lacking mediobasal foveae and basal impression, with small basolateral foveae. Foveal pattern of remaining abdominal segments barely visible based on available specimen, but one pair of basolateral foveae putatively present on each of tergites 2-4 (V-VII).

Legs moderately elongate; all three pairs of coxae contiguous; metacoxae (Fig. 2C; $m t c$ ) moderately projecting posteriorly; dorsal margin of all trochanters short, base of femora thus close to coxal-trochanteral articulation. Tarsi three-segmented (Fig. 2 box; $11-3$ ), with short tarsomere 1 , and longer tarsomeres 2 and 3; tarsomere 2 distinctly shorter than tarsomere 3 ; tarsi each with one elongate claw (Fig. 2 box; tc). Male mesotrochanters and mesotibiae modified on ventral margin and at near apex, respectively; fore and hind legs simple.

Etymology. The generic name is a combination of the prefix 'Creto-' derived from the Cretaceous, and Brachygluta Thomson, 1859, type genus of Brachyglutini. The gender is feminine. $\uparrow$ Cretobrachygluta laurasiensis sp. nov.

Type material. НоцотуPE (SNUC-Paleo-0076): a well-preserved male in an approximately $7.2 \times 5.0 \mathrm{~mm}$ clear, yellowish amber piece; upper Albian to lower Cenomanian, Hukawng Valley, northern Myanmar (SNUC).

Diagnosis of male. As for the genus (vide supra), plus the following: body length $1.85 \mathrm{~mm}$; mesotrochanters protuberant at ventral margin; mesotibiae with small, triangular preapical spur.

Description. Habitus (Fig. 1) rather stout; total body length (combined length of head, pronotum, elytra, and abdomen) $1.85 \mathrm{~mm}$. Body reddish brown, with mouthparts and tarsi paler, integument of dorsal surface densely covered with suberect fine setae. Head slightly broader than long; length from anterior margin of clypeus toward base $0.30 \mathrm{~mm}$, width across eyes $0.41 \mathrm{~mm}$; eyes roundly prominent, each composed of approximately 75 facets. Length of antenna $0.86 \mathrm{~mm}$; antennomere I (scape) cylindrical, about 1.65 times as long as wide, antennomere II (pedicel) roundedcylindrical, much narrower than scape, 1.2 times as long as 

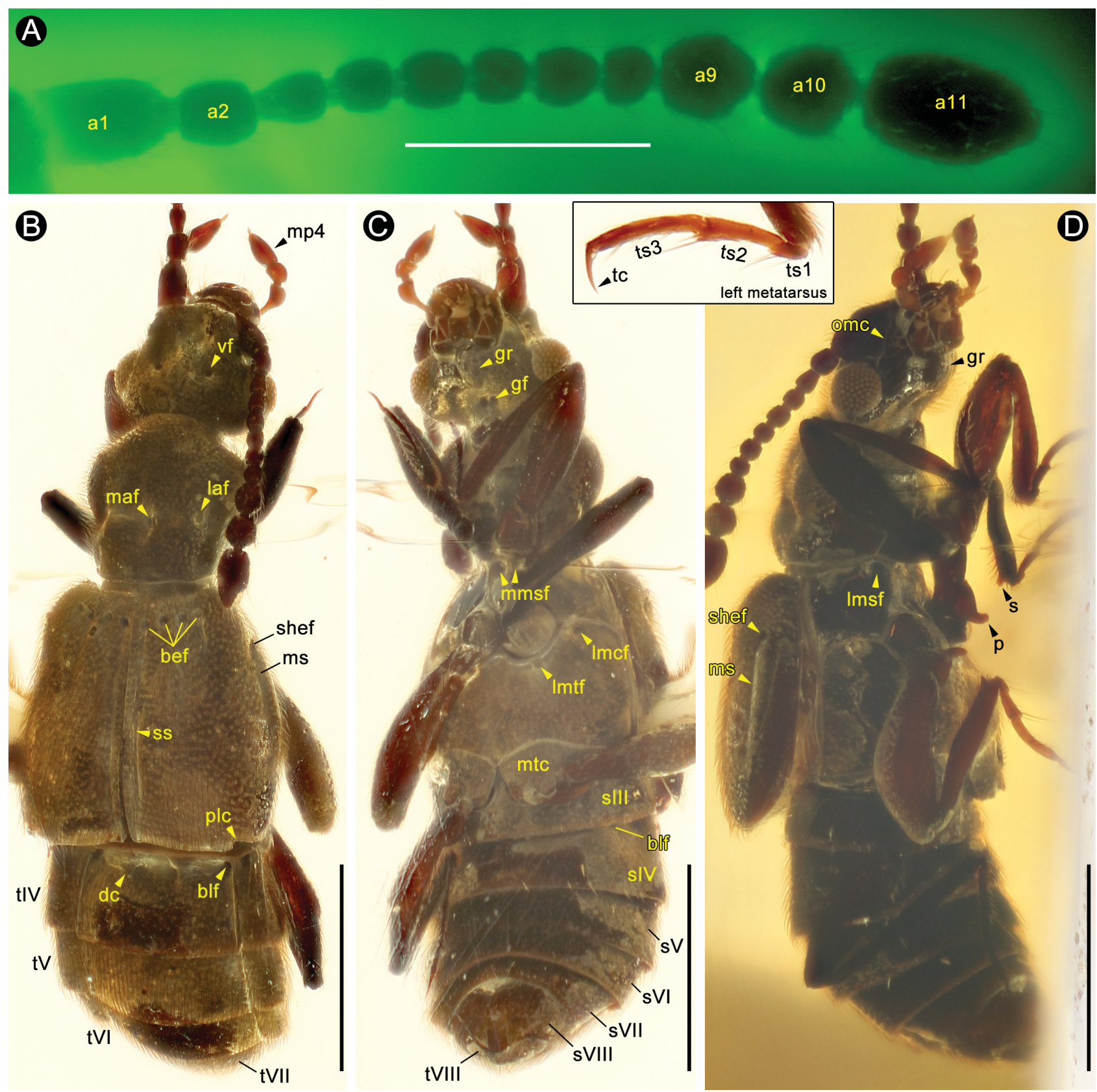

D

Fig. 2. Morphological details of $\uparrow$ Cretobrachygluta laurasiensis gen. et sp. nov. A - left antenna; B-D - main body parts in dorsal (B), ventral (C), and lateral (D) view, with foveal pattern and other important characters annotated. Scale bar: $0.2 \mathrm{~mm}$ in A; $0.5 \mathrm{~mm}$ in B-D. Abbreviations: a1-2, 9-11 = antennomeres 1-2, 9-11; bef = basal elytral foveae; blf = basolateral fovea; $\mathrm{dc}=$ discal carina; $\mathrm{gf}=$ gular fovea; gr = gular ridge; laf = lateral antebasal fovea; $1 \mathrm{mcf}=$ lateral mesocoxal fovea; $1 \mathrm{msf}=$ lateral mesoventral fovea; $1 \mathrm{mtf}=$ lateral metaventral fovea; maf = median antebasal fovea; $\mathrm{mmsf}=$ median mesoventral foveae; $\mathrm{mp} 4=$ maxillary palpomere $4 ; \mathrm{ms}=$ marginal stria; $\mathrm{mtc}=$ metacoxa; omc $=$ ocular-mandibular carina; $\mathrm{p}=$ projection; plc $=$ posterolateral cleft; s = spur; shef = subhumeral elytral fovea; sIII-VIII = sternites III-VIII; ss = sutural stria; tIV-VIII = tergites IV-VIII; tc = pretarsal claw; ts $1-3=$ tarsomeres $1-3$; vf = vertexal fovea.

wide, and about 0.6 times as long as scape, antennomeres 3-7 almost moniliform, slightly elongate, antennomere 8 distinctly transverse, antennomeres 9-11 obconical, successively wider apically, antennomere 11 about twice as long as antennomere 10, truncate at base, broadest at near middle, and narrowing toward apex, with inner margin broadly emarginate in apical half (observable in Fig. 1A, right antenna). Maxillary palpi as in Figs 2B-D; length of palpomere $10.03 \mathrm{~mm}$, palpomere $20.12 \mathrm{~mm}$, palpomere 3 $0.06 \mathrm{~mm}$, palpomere $40.12 \mathrm{~mm}$. Pronotum slightly longer than wide, length along midline $0.41 \mathrm{~mm}$, maximum width $0.37 \mathrm{~mm}$; sides roundly expanded laterally. Elytra transverse, length along suture $0.58 \mathrm{~mm}$, maximum width 0.66 $\mathrm{mm}$, anterior margin broadly impressed, posterior margin truncate. Legs moderately elongate, densely setose; ventral margin of mesotrochanters projecting in conspicuous process; mesotibiae bearing small, triangular preapical spur. Abdomen broadest at tergite 1 (IV), length along midline $0.66 \mathrm{~mm}$, maximum width $0.57 \mathrm{~mm}$; tergites and sternites densely covered with suberect, posteriorly directed setae; 
tergite VIII with deep apical notch at middle of posterior margin.

Remarks. The protuberant mesotrochanters, spinose mesotibiae, and apically notched tergite VIII are interpreted as male sexual characters based on our experience in the extant brachyglutine fauna.

Etymology. The specific epithet refers to the occurrence of this species on the supercontinent Laurasia some 99 million years ago. Adjective.

\section{Discussion}

$\uparrow$ Cretobrachygluta possesses a number of characters that suggest its placement within the extant tribe Brachyglutini: subtribe Brachyglutina, especially: 1) the gular region has a broad median ridge laterally demarcated by a pair of sulci (Figs 2C, 2D), which was considered an apomorphy for Brachyglutina (Kurbatov \& SABElla 2015), and 2) the typical brachyglutine form of the maxillary palpi (i.e., short and subtriangular third, and large, ovoidal, and basally truncate fourth palpomeres; Figs 2C-D). The placement of $\dagger$ Cretobrachygluta within Brachyglutini is also evidenced by the congruent foveal pattern of the thorax, the well-developed and demarcated paratergites, and the structures of the abdomen which are typical for the tribe.

Notwithstanding, $†$ Cretobrachygluta embodies the following characters that are unusual for a general Brachyglutini morphology: 1) sternite 1 (III) is long, clearly visible along its entire width between and behind the metacoxae (Fig. 2C), 2) the metatrochanters are contiguous (Fig. 2C), 3 ) the tarsomeres 2 are distinctly shorter than tarsomeres 3 (Fig. 2, box), and 4) the median mesoventral foveae are narrowly separated (Fig. 2C) (to our knowledge, within Brachyglutina this character state is only found in the genus Batraxis Reitter, 1881). These characters may indicate the need for a new higher taxon for the new genus, but in the absence of an adequate internal classification of Brachyglutini and adjacent taxa, the uncertainty of the relationships between them, and the fact that $\dagger$ Cretobrachygluta shows no clear apomorphies, we refrain from proposing a new taxon beyond generic rank. At this moment, we simply consider the situation as an implication for the evolutionary trend of the ancestral/derived state of these characters, and therefore treat $\dagger$ Cretobrachygluta as a member of stem group Brachyglutini.

To test the phylogenetic placement of $\dagger$ Cretobrachygluta within Pselaphinae, we also performed a maximum parsimony analysis by integrating the new fossil taxon into a previous published dataset (YIN et al. 2017). Our preliminary result (50\% majority-rule consensus) showed that $\dagger$ Cretobrachygluta was included in a polytomy containing genera Rybaxis Saulcy, 1876 (Brachyglutini), Reichenbachia Leach, 1826 (Brachyglutini), and Harmophorus Motschulsky, 1851 (Arnylliini) (all belong to Goniaceritae), and a lineage comprising Bythinini (Goniaceritae) + Pselaphitae and Clavigeritae. Support of this entire clade, however, was weak (authors' pers. obs., bootstrap value $=15$, tree not shown here), indicating a new dataset of a much boarder taxa sampling range is required for future analyses.
Currently, the tribe Brachyglutini holds 117 genera worldwide (Chandler 2001, KuRbatov \& Sabella 2015, YIN \& HLAVÁČ 2016), among which †Cretobrachygluta appears to be most similar to the genus Physoplectus Reitter, 1882 in sharing a generally elongate body, relatively large third palpomeres (in relation to fourth palpomeres) of the maxillary palpi, well-marked antennal clubs, the presence of subhumeral foveae and marginal striae of the elytra, and a similar set of characters of abdominal tergite 1 (IV) (except for the presence of the shallow basal impression), etc. However, Physoplectus can be readily distinguished by the foveae of the head and pronotum being setose (nude in $\uparrow$ Cretobrachygluta), presence of only two basal foveae and elongate discal striae of the elytra (four basal foveae and no discal stria of $\dagger$ Cretobrachygluta), as well as the lack of many plesiomorphic traits that are present in $†$ Cretobrachygluta (see previous paragraph).

Considering the scarcity of fossil pselaphines from the global Mesozoic deposits, the discovery of $\uparrow$ Cretobrachygluta in Burmese amber is important for a better understanding of the early morphological evolution of Goniaceritae, which also provides direct evidence that the advanced general body plan of modern Brachyglutini has been established at least for 99 million years.

\section{Acknowledgments}

We thank Donald S. Chandler (University of New Hampshire, Durham, USA) for a helpful discussion on the placement of the new genus. Alfred F. Newton (Field Museum of Natural History, Chicago, USA) provided exact species number of Pselaphinae based on his personal database. Margaret K. Thayer (Field Museum of Natural History, Chicago, USA) and one anonymous reviewer provided critical comments which greatly improved the manuscript. Financial supports was provided by the Strategic Priority Research Program of Chinese Academy of Sciences (XDB26000000), and the National Nature Science Foundation of China (31872965), and Shanghai 'Phosphor' Science Foundation, China (2019-2022) awarded to ZWY.

\section{References}

CHANDLER D. S. 2001: Biology, morphology, and systematics of the ant-like litter beetles of Australia (Coleoptera: Staphylinidae: Pselaphinae). Memoirs on Entomology, International 15: i-viii + 1-560.

CHHIBBER H. L. 1934: The Mineral Resources of Burma. MacMillan, London, $320 \mathrm{pp}$.

CRUICKSHANK R. D. \& KO K. 2003: Geology of an amber locality in the Hukawng Valley, northern Myanmar. Journal of Asian Earth Sciences 21: 441-455.

GRIMALDI D. A., ENGEL M. S. \& NASCIMBENE P. C. 2002: Fossiliferous Cretaceous amber from Myanmar (Burma): its rediscovery, biotic diversity, and paleontological significance. American Museum Novitates 3361: 1-72.

GRIMALDI D. A. \& ROSS A. J. 2017: Extraordinary Lagerstätten in amber, with particular reference to the Cretaceous of Burma. Pp. 287-342. In: FRASER N. C. \& SUES H.-D. (eds): Terrestrial Conservation Lagerstätten: Windows into the Evolution of Life on Land. Dunedin Academic Press, Edinburgh, 356 pp.

KANIA I., WANG B. \& SZWEDO J. 2015: Dicranoptycha Osten Sacken, 1860 (Diptera, Limoniidae) from the earliest Cenomanian Burmese amber. Cretaceous Research 52: 522-530. 
KURBATOV S. A. \& SABELlA G. 2015: A revision of the Chilean Brachyglutini. Part. 1. Some taxonomic changes in Brachyglutini and preliminary diagnosis of Achilia Reitter, 1890 (Coleoptera: Staphylinidae: Pselaphinae). Revue Suisse de Zoologie 122: 297-306.

LAWRENCE J. F., BEUTEL R. G., LESCHEN R. A. B. \& ŚLIPIŃSKI A. 2010: 2. Glossary of morphological terms. Pp. 9-20. In: LESCHEN R. A. B., BEUTEL R. G. \& LAWRENCE J. F. (eds.): Handbook of Zoology. Arthropoda: Insecta. Coleoptera, Beetles Volume 2: Morphology and Systematics (Elateroidea, Bostrichiformia, Cucujiformia partim). Walter de Gruyter, GmbH \& Co., Berlin/New York, xiii + 786 pp.

MAO Y., LIANG K., SU Y., LI J., RAO X., ZHANG H., XIA F., FU Y., CAI C. \& HUANG D. 2018: Various amberground marine animals on Burmese amber with discussions on its age. Palaeoentomology 1: 91-103.

NEWTON A. F. \& CHANDLER D. S. 1989: World catalog of the genera of Pselaphidae (Coleoptera). Fieldiana, Zoology (New Series) 53: 1-93.

NEWTON A. F. \& THAYER M. K. 1995: Protopselaphinae new subfamily for Protopselaphus new genus from Malaysia, with a phylogenetic analysis and review of the Omaliine Group of Staphylinidae including Pselaphidae (Coleoptera). Pp. 219-320. In: PAKALUK J. \& ŚLIPIŃSKI A. (eds.): Biology, Phylogeny, and Classification of Coleoptera: Papers Celebrating the 80th Birthday of Roy A. Crowson. Muzeum i Instytut Zoologii PAN, Warszawa, 1092 pp.

OKE C. 1957: Fossil Insecta from Cainozoic resin at Allendale, Victoria. Proceedings of the Royal Society of Victoria (New Series) 69: 29-31.

PARKER J. 2016: Emergence of a superradiation: pselaphine rove beetles in mid-Cretaceous amber from Myanmar and their evolutionary implications. Systematic Entomology 41: 541-566.
RASNITSYN A. P., BASHKUEV A. S., KOPYLOV D. S., LUKASHEVICH E. D., PONOMARENKO A. G., POPOV Y. A., RASNITSYN D. A., RYZHKOVA O. V., SIDORCHUK E. A., SUKATSHEVA I. D. \& VORONTSOV D. D. 2016: Sequence and scale of changes in the terrestrial biota during the Cretaceous (based on materials from fossil resins). Cretaceous Research 61: 234-255.

ROSS A. J., MELLISH C. \& CRIGHTON B. 2010: Burmese amber. Pp. 208-235. In: PENNEY D. (ed.): Biodiversity of fossils in amber from the major world deposits. Siri Scientific Press, Manchester, 304 pp.

SCHAUFUSS L. W. 1890: System-schema der Pselaphiden, ein Blick in die Vorzeit, in die Gegenwart und in die Zukunft. Tijdschrift voor Entomologie 33: 101-162.

SHI G., GRIMALDI D. A., HARLOW G. E., WANG J., WANG J., YANG M., LEI W., LI Q. \& LI X. 2012: Age constraint on Burmese amber based on U-Pb dating of zircons. Cretaceous Research 37: 155-163.

YIN Z., CAI C. \& HUANG D. 2018: Last major gap in scydmaenine evolution filled (Coleoptera: Staphylinidae). Cretaceous Research 84: 62-68.

YIN Z.-W. \& HLAVÁČ P. 2016: The Pselaphinae (Coleoptera, Staphylinidae) of New Caledonia and Loyalty Islands. III. Kieneriella, a new genus of the tribe Brachyglutini. Deutsche Entomologische Zeitschrift 63: 149-154.

YIN Z.-W., PARKER J., CAI C.-Y., HUANG D.-Y. \& LI L.-Z. 2017: A new stem bythinine in Cretaceous Burmese amber and early evolution of specialized predatory behaviour in pselaphine rove beetles (Coleoptera: Staphylinidae). Journal of Systematic Palaeontology: https://doi.org/10.1080/14772019.2017.1313790. [volume and issue information and pagination were assigned in 2018 as follows: 16(7): 531-541] 